\title{
Article \\ Pyridine-Based Three-Ring Bent-Shape Supramolecular Hydrogen Bond-Induced Liquid Crystalline Complexes: Preparation and Density Functional Theory Investigation
}

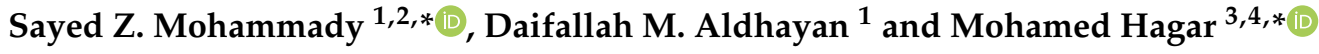 \\ 1 Chemistry Department, Faculty of Science, King Saud University, P.O. Box 2455, Riyadh 11451, Saudi Arabia; \\ aldhayan@ksu.edu.sa \\ 2 Chemistry Department, Faculty of Science, Cairo University, Giza P.O. Box 12613, Egypt \\ 3 Chemistry Department, College of Sciences, Taibah University, Yanbu 30799, Saudi Arabia \\ 4 Chemistry Department, Faculty of Science, Alexandria University, Alexandria P.O. Box 21321, Egypt \\ * Correspondence: sahmed2.c@ksu.edu.sa (S.Z.M.); mohamedhaggar@gmail.com (M.H.)
}

check for updates

Citation: Mohammady, S.Z.; Aldhayan, D.M.; Hagar, M. Pyridine-Based Three-Ring Bent-Shape Supramolecular Hydrogen Bond-Induced Liquid Crystalline Complexes: Preparation and Density Functional Theory Investigation. Crystals 2021, 11, 628 https://doi.org/10.3390/ cryst11060628

Academic Editors: Chenhui Peng, Dmitry A. Bedrov, Shuang Zhou and Rajratan Basu

Received: 25 April 2021

Accepted: 26 May 2021

Published: 31 May 2021

Publisher's Note: MDPI stays neutral with regard to jurisdictional claims in published maps and institutional affiliations.

Copyright: (c) 2021 by the authors. Licensee MDPI, Basel, Switzerland. This article is an open access article distributed under the terms and conditions of the Creative Commons Attribution (CC BY) license (https:/ / creativecommons.org/licenses/by/ $4.0 /)$.

\begin{abstract}
A series of new supramolecular three-ring bent-shape Schiff base liquid crystal (LC) complexes were prepared and studied. On one side, two alkoxy chain lengths of the carboxylic acids were used, namely eight and sixteen carbons. Moreover, on the other side, terminal small compact groups, which substituted aniline, with different polarities were utilized. Furthermore, the hydrogen-bonding interactions in the formed complexes were elucidated by Fourier-transform infrared (FT-IR) spectroscopy. The mesomorphic thermal and optical characteristics of the samples were determined by differential thermal analysis (DSC) and polarized optical microscopy (POM). The complexes exhibited enantiotropic and dimorphic mesophase behaviors. The results indicate that the polarity of the compact groups and the lengths of the alkoxy chains greatly impacted the mesomorphic characteristics and thermal stabilities of the mesophases. The observed values of the enthalpy changes $(\Delta \mathrm{H})$ associated with the crystalline smectic-A $\left(\mathrm{T}_{\mathrm{Cr}-\mathrm{SmA}}\right)$ transitions were extremely small compared with the conventional values that characterize supramolecular hydrogen-bonded liquid crystalline complexes. $\Delta \mathrm{H}$, which corresponded to the nematic isotropic transitions $\left(\mathrm{T}_{\mathrm{N}-\mathrm{I}}\right)$, varied from 0.13 to $9.54 \mathrm{~kJ} / \mathrm{mol}$ depending mainly on the polarity of the groups that were paraattached to the aniline moiety. Finally, the theoretical results obtained by density functional theory (DFT) calculations were discussed. The DFT geometrical structures showed non-coplanar structures. The mesomorphic range was correlated with the calculated dipole moment, polarizability and the aspect ratios of the investigated compounds.
\end{abstract}

Keywords: supramolecular; bent-shape; Schiff base; liquid crystal complex; mesophase; enantiotropic; dimorphic

\section{Introduction}

Supramolecular aggregation arises from the binding of a group of molecules with welldefined structures. These molecules are grouped by second-order (non-covalent) bonds, e.g., hydrogen bonds, halogen bonds, pi agglutination, van der Waals forces, coordination bonds, and dipole-dipole interactions [1-3]. Liquid crystals (LCs) are among the most valuable formative materials that can be produced by supramolecular assembling [4-7], and these generated assemblies in LCs have been employed in diverse applications [8-12].

Hydrogen bonds are probably the most valuable among the second-order bonds owing to their essential role in supramolecular compounds. The term "hydrogen bond" was first employed by Pauling [13], who postulated that hydrogen bonds exhibited an electrostatic characteristic. This concept evolved over six decades before Steiner and Singer [14] (in the early 1990s) defined hydrogen bonding as any attraction of the type " $\mathrm{X}-\mathrm{H} \cdots \mathrm{A}$ ", where $\mathrm{H}$ and A possess partially positive and partially negative charges, respectively. The charge on 
the $\mathrm{X}$ atom is more negative than that on the H atom. This concept indicates the possibility of variations in hydrogen bond strengths depending on the properties of the atoms in the bond (electronegativity).

Hydrogen bonds are partially responsible for the generation of supramolecular liquidcrystalline assemblies. Two-component self-assembly can be generally achieved through thermal (melt) mixing or dissolution, followed by the two-component reaction through hydrogen bonding [15-17]. Generally, a hydrogen-bonded (H-bonded) complex based on a multicomponent system is a very important tool to generate new meso- genic designs. $\mathrm{H}$-bonding was utilized to originate the mesogenic core of calamitic LCs giving rise to the widely studied field of hydrogen bonded LCs. In H-bonded LC heterodimers, the rigid mesogenic core is formed through the $\mathrm{H}$-bond between a hydrogen bond donor and a hydrogen bond acceptor. Various hydrogen bond donors, including benzoic acids [18], alkanoic acids [19-21], and nitro-phenols [22], and H-bond acceptors, including alkyl substituted pyridines [23], stilbazoles [22,24], aldehydes and ketones [25], were used to form H-bonded heterodimers. The phase transition temperatures and the textures of the LC phases in these $\mathrm{H}$-bonded heterodimers were found to be dependent on the identities of the H-bond donors and acceptors [19,21,26-28]. In addition, pyridine-based supramolecular $\mathrm{H}$-bonded LCs have attracted the interest of many researchers in the past two decades for various systems [29-34].

Moreover, hydrogen bonding has been applied to a wide range of academic research [35-37], and it is relevant at an industrial level [36,38]. For example, hydrogen bonding in LCs can improve the performance of LC displays (LCDs). Furthermore, hydrogen bonding exists between the host LC and the guest dispersed dichroic dye molecules $[36,39,40]$. LCDs are a major application of LC in the industry. They consist basically of two panels with perpendicular polarizations, and LCs are the active component among the two panels and are characterized by a dichroic dye that is dissolved in them.

The results of the differential scanning calorimetry (DSC) of LCs, even for those produced through supramolecular assemblies, generally featured relatively high enthalpy changes $(\Delta \mathrm{H})$, accompanied by crystalline mesomorphic transitions (20-100 kJ/mol) [41-47]. However, the literature reports some examples in which the $\Delta \mathrm{H}$ values during melting were lower than $10 \mathrm{~kJ} / \mathrm{mol}$ [48-51].

Here, a series of novel supramolecular three-ring Schiff base-induced LC complexes were prepared and investigated. The Schiff bases of para-substituted aniline derivatives and para-pyridine carbaldehyde were prepared and mixed with para-alkoxy benzoic acids in equimolar quantities. Two alkoxy chain lengths were used, namely C8 and C16. On the other side, small terminal compact groups, namely the Me, chloro, bromo, fluoro, and nitro groups with various polarities, which substituted aniline, were utilized. Hydrogen-bonding interactions were expected to occur and induce the three-ring hydrogenbonded LCs. Furthermore, the alkoxy acid was considered as the source of hydrogen bonding, while the pyridine structural units represented the hydrogen bond acceptors. The mesomorphic thermal and optical characteristics of the samples were investigated by DSC and polarized optical microscopy (POM). Notably, the system under investigation generally possesses extremely low crystalline mesomorphic $\Delta H$ s. Finally, the experimental results were correlated with the theoretical results obtained by density functional theory (DFT) calculations.

\section{Results and Discussion}

\subsection{Fourier-Transform Infrared (FT-IR) Characterizations}

The non-mesomorphic nitrogen-based component was prepared by the condensation of 3-pyridine carbaldehyde with arylamines. The Schiff bases were utilized to prepare the supramolecular hydrogen-bonded complexes $((\mathbf{I}-\mathbf{V}) \mathbf{C n})$. Each Schiff base was mixed with the corresponding alkoxy benzoic acid in a 1:1 molar ratio at a particular chain length $(n=8$, and 16). The formations of the complexes were proven by FT-IR and nuclear magnetic resonance (NMR) spectral analyses [52-56]. However, the FT-IR measurements proved 
to be an effective tool for such confirmations [56-60]. The spectral data of the compounds $(\mathbf{C} 8, \mathbf{I})$, and I/C8 were measured, as shown in Figure 1a-C, where C8, I, and II/C8 represent p-octyloxybenzoic acid, the Me Schiff base, and the complex, respectively.
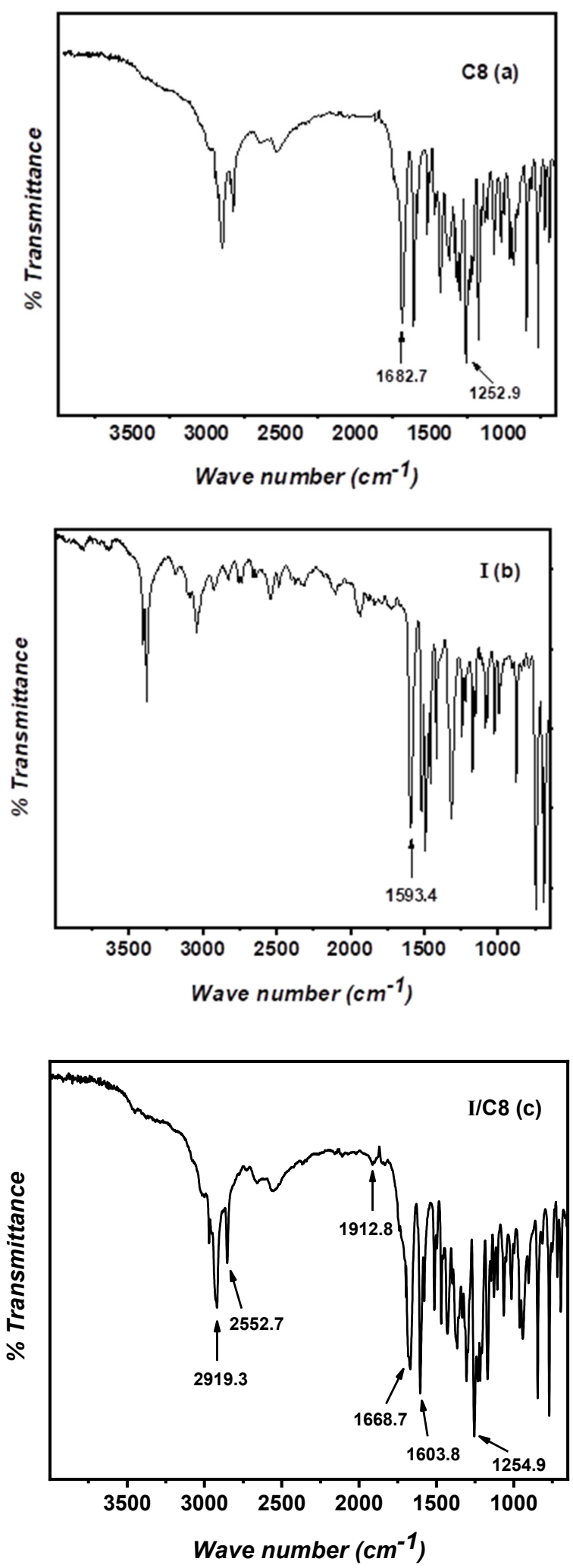

Figure 1. (a-c) FT-IR spectra of para-octyloxy benzoic acid (C8), the methyl Schiff base (I), and the complex I/C8 in charts $(\mathbf{a}-\mathbf{c})$, respectively. 
The existence of the prepared supramolecular hydrogen-bonded complexes was revealed by FT-IR (Figure 1a-c). The measurements were performed for the free acids $(\mathrm{Cn})$ and Schiff bases (I-V), as well as for their corresponding supramolecular complexes $[(\mathbf{I}-\mathbf{V}) \mathbf{C n}]$.

Figure 1a reveals a signal at $1682.7 \mathrm{~cm}^{-1}$, which corresponded to the $\mathrm{C}=\mathrm{O}$ group of the alkoxy acid in its free form $(-\mathrm{COOH})$.

In our system, the H-bond donor is the para-alkoxy benzoic acid and $\mathrm{H}-$-bond acceptor is the pyridine ring participating in the substituted Schiff bases. The hydrogen bonds between the nitrogen atom of the pyridine Schiff base portion (I) and the hydrogen donor (para-octyloxy benzoic acid (C8)) of the supramolecular complex (I/C8) shifted the stretching vibrations of the $\mathrm{C}=\mathrm{O}$ group from 1682.7 to $1668.7 \mathrm{~cm}^{-1}$, which was attributed to the existence of hydrogen-bonding in prepared supramolecular complexes. This evident redshift in the wavenumber values (lowered by $14.0 \mathrm{~cm}^{-1}$ ) indicated that the formation of the $\mathbf{I} / \mathbf{C} 8$ complex exerted an intensively negative effect on the $\mathrm{C}=\mathrm{O}$ ester of the acid.

The FT-IR results were further expanded to prove the existence of hydrogen bonding in the complexes through the presence of the three Fermi resonance-induced vibrational bands, which accompanied the formation of hydrogen bonds in the complexes. The vibrational bands at 2919.3, 2852.7, and $1912.8 \mathrm{~cm}^{-1}$ (Figure 1c) were attributed to the A-, B-, and C-type Fermi bands, respectively. The appearance of the A-type band and the disappearance of the stretching vibration of the free OH group at $\sim 3500 \mathrm{~cm}^{-1}$ confirmed the contribution of the $\mathrm{OH}$ component of the carboxylic group to hydrogen bonding [61]. Additionally, the band at $2852.7 \mathrm{~cm}^{-1}$ (Figure 1c) could be attributed to the $\mathrm{O}-\mathrm{H}$ in-plane bending vibration, as well as its associated fundamental stretching (B type). The third band at $1912.8 \mathrm{~cm}^{-1}$ (type-C Fermi band) corresponded to the interaction between the overtone of the torsional effect and the fundamental stretching vibration of the $\mathrm{OH}$ group.

A blue shift was observed in the peak maximum of the etheric $\mathrm{C}-\mathrm{O}$ bond in the acid during the formation of the complex. The peak maximum of the $\mathrm{C}-\mathrm{O}$ bond in the acid was revealed at $1252.9 \mathrm{~cm}^{-1}$ (Figure 1a), while it was observed at $1254.9 \mathrm{~cm}^{-1}$ in the complex (Figure 1c).

Moreover, a significant blue shift of the wavenumber from $1593.4 \mathrm{~cm}^{-1}$ (Figure $1 \mathrm{~b}$ ) to 1603.8 was observed in the complex (Figure 1c), and it corresponded to the $-\mathrm{CH}=\mathrm{N}-$ Schiff base characteristic peak. This evident increase in the absorption peak that characterized the azomethine group $\left(10.4 \mathrm{~cm}^{-1}\right)$ could be considered as an additional confirmation of hydrogen-bonding in the supramolecular complexes.

Furthermore, the mesophase, as well as the optical analyses, of the 1:1 three-ring $((\mathbf{I}-\mathbf{V}) \mathbf{C n})$ complexes were investigated. The transition temperatures $(T \mathrm{~s})$ and associated $\Delta H$ s, during the mesophase transitions, as derived by the DSC measurements, are summarized in Table 1.

Table 1. Phase transitions: temperatures $\left(T,{ }^{\circ} \mathrm{C}\right)$ andenthalpies $(\Delta H, \mathrm{~kJ} / \mathrm{mol})$ for the $((\mathbf{I}-\mathbf{V}) \mathbf{C n})$ complexes.

\begin{tabular}{|c|c|c|c|c|c|c|c|c|c|}
\hline \multirow{2}{*}{\multicolumn{2}{|c|}{ Compounds }} & \multirow{2}{*}{$\begin{array}{c}{ }^{\circ} \mathrm{C} \\
\mathrm{T}_{\mathrm{Cr}-\mathrm{SmA}}\end{array}$} & \multirow{2}{*}{$\begin{array}{c}\mathrm{kJ} / \mathrm{mol} \\
\Delta \mathrm{H}_{\mathrm{Cr}-\mathrm{SmA}}\end{array}$} & \multirow{2}{*}{$\frac{{ }^{\circ} \mathrm{C}}{\mathrm{T}_{\text {SmA-N }}}$} & \multirow{2}{*}{$\frac{\mathrm{kJ} / \mathrm{mol}}{\Delta \mathrm{H}_{\mathrm{SmA}-\mathrm{N}}}$} & \multirow{2}{*}{$\frac{{ }^{\circ} \mathrm{C}}{\mathrm{T}_{\text {SmA-I }}}$} & \multirow{2}{*}{$\frac{\mathrm{kJ} / \mathrm{mol}}{\Delta \mathrm{H}_{\mathrm{SmA}-\mathrm{I}}}$} & \multirow{2}{*}{$\frac{{ }^{\circ} \mathrm{C}}{\mathbf{T}_{\mathrm{N}-\mathrm{I}}}$} & \multirow{2}{*}{$\frac{\mathrm{kJ} / \mathrm{mol}}{\Delta \mathrm{H}_{\mathrm{N}-\mathrm{I}}}$} \\
\hline & & & & & & & & & \\
\hline I/C8 & C8-Me & 75.8 & 2.01 & 100.5 & 1.66 & & & 144.3 & 0.34 \\
\hline $\mathrm{II} / \mathrm{C} 8$ & $\mathrm{C} 8-\mathrm{Cl}$ & 68.2 & 4.99 & 75.6 & 1.82 & & & 96.0 & 0.15 \\
\hline III/C8 & $\mathrm{C} 8-\mathrm{Br}$ & 63.2 & 1.12 & 77.5 & 2.35 & & & 86.4 & 0.06 \\
\hline IV/C8 & C8-F & 52.1 & 3.23 & 74.9 & 0.89 & & & 89.4 & 0.20 \\
\hline $\mathrm{V} / \mathrm{C} 8$ & $\mathrm{C} 8-\mathrm{NO}_{2}$ & 74.4 & 1.22 & 98.1 & 0.97 & & & 133.0 & 0.99 \\
\hline I/C16 & C16-Me & 54.3 & 4.92 & 91.3 & 11.10 & & & 121.1 & 6.22 \\
\hline II/C16 & $\mathrm{C} 16-\mathrm{Cl}$ & 65.7 & 2.15 & & & 95.1 & 7.70 & & \\
\hline III/C16 & C16-Br & 67.5 & 4.05 & 94.1 & 10.68 & & & 130.3 & 2.70 \\
\hline IV/C16 & C16-F & 65.8 & 4.17 & 94.8 & 7.70 & & & 118.5 & 4.10 \\
\hline V/C16 & $\mathrm{C} 16-\mathrm{NO}_{2}$ & 102.0 & 5.70 & 116.4 & 4.30 & & & 139.3 & 6.03 \\
\hline
\end{tabular}


The mesophase and optical analysis for the three rings 1:1 ((C8) complexes were investigated. Transition temperatures $(T)$ and their associated enthalpies $(\Delta H)$ of all mesophase transitions, as derived from DSC measurements, for all prepared $((\mathbf{I}-\mathbf{V}) \mathbf{C n})$ complexes are summarized in Table 1.

Figure 2a shows the DSC thermograms of sample $\mathrm{C} 8-\mathrm{Me}$ at a heating rate of $10.0^{\circ} \mathrm{C} / \mathrm{min}$. The first heating run was carried out from room temperature up to $150{ }^{\circ} \mathrm{C}$ to avoid any possible thermal degradation. However, the second heating run covers the temperature range from room temperature to $18{ }^{\circ} \mathrm{C}$. All samples revealed thermal stabilities at the investigated range of temperature. We discussed the results that were obtained from only the second heating run. The temperature dependence of the heat capacity exhibited an endothermic peak at $75^{\circ} \mathrm{C}$, which corresponded to a crystalline nematic (Cr-SmA) phase transition. At elevated temperatures, a second endothermic peak, which revealed a smecticA-nematic (SmA-N) transition, was observed at $100.5^{\circ} \mathrm{C}$. Finally, a nematic-isotropic (N-I) transition was observed at $144.3^{\circ} \mathrm{C}$. Upon cooling, the nematic phase peak maximum appears at $140.5^{\circ} \mathrm{C}$ and the SmA mesophase peak maximum appears at $93.7^{\circ} \mathrm{C}$. The crystalline solid is formed at $58.4^{\circ} \mathrm{C}$, indicating a supercooling behavior. In addition, the types of the different mesophase textures were distinguished by POM. Figure $2 \mathrm{~b}$ represents the nematic mesophase texture of sample C8-Me at $120^{\circ} \mathrm{C}$.

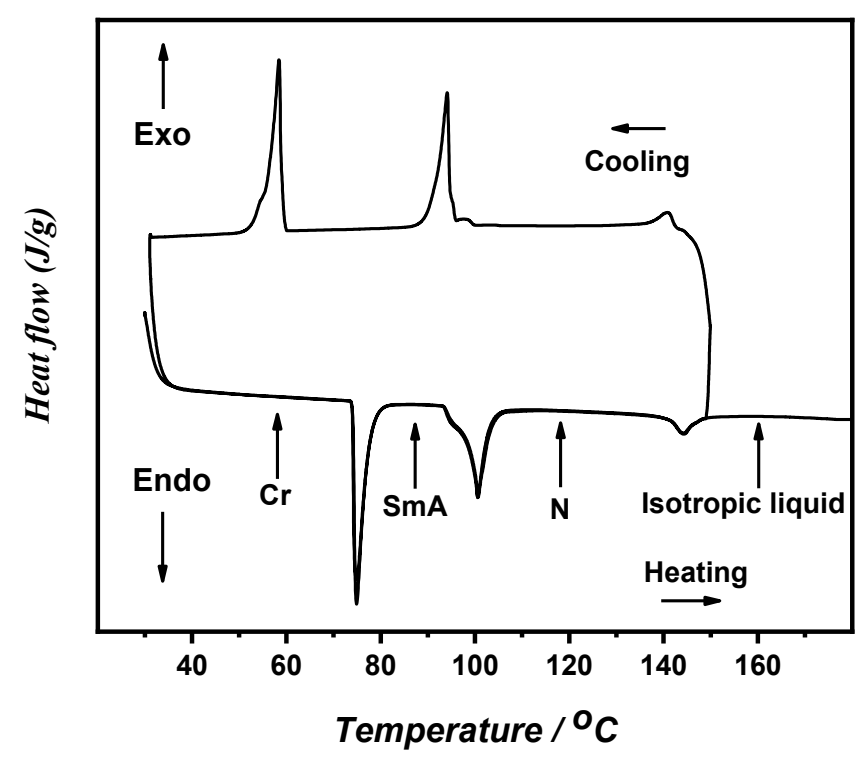

(a)

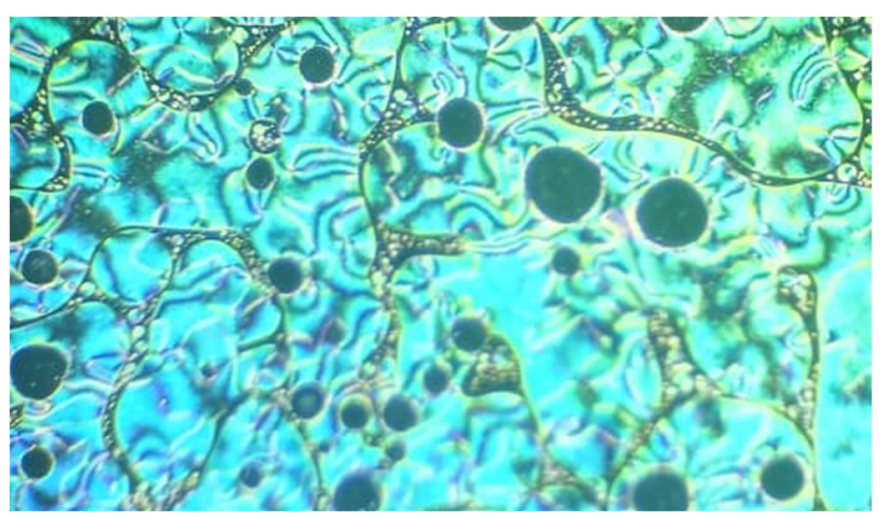

(b)

Figure 2. (a) DSC heating/cooling cycles of the I-C8 methyl complex liquid crystalline sample. (b) POM results upon heating at $120^{\circ} \mathrm{C}$ revealing the nematic phase for I-C8 methyl complex liquid crystalline sample. 
The analogous series of the $\mathbf{C 8}$ chain lengths of the attached polar groups were investigated regarding Ts with respect to the forms of the polar groups. Figure 3 shows a representative of the prepared hydrogen-bonded supramolecular complexes. The polar groups exhibited dimorphic SmA and $\mathrm{N}$ behaviors. The electron-releasing Me group exhibited SmA and $\mathrm{N}$ mesophase ranges of 24.7 and $43.8^{\circ} \mathrm{C}$, respectively (a total mesomorphic range of $68.5^{\circ} \mathrm{C}$ ). However, the halide derivatives exhibited overall mesomorphic ranges of $37.3,27.8,23.2^{\circ} \mathrm{C}$ for $\mathrm{F}, \mathrm{Cl}$, and $\mathrm{Br}$, respectively, which indicated a systematic decrease in the range as a function of decreasing electronegativity and increasing size of the halide substituent. However, the highly electron-withdrawing $\mathrm{NO}_{2}$ group exhibited a mesomorphic range of $58.6^{\circ} \mathrm{C}$. The wider mesophase ranges of the $\mathrm{Me}$ and $\mathrm{NO}_{2}$ derivatives could be explained by the hyperconjugation and resonance effects, respectively. Both effects could increase the $\pi$-cloud loop and enhance the degree of $\pi-\pi$ stacking in the Me and $\mathrm{NO}_{2}$ complexes compared with in the fluoro, chloro, and bromo derivatives. The attachment of the halide atom was compared with the mesomorphic properties, as shown in Figure 3. The Cl-substituted complex exhibited an $\mathrm{N}$ range of $20.4^{\circ} \mathrm{C}$, which corresponded to the end-end interaction due to the increased dipole moment that was exerted by the strong negative inductive effect of the chloride group. The incorporation of the small compact fluorine atom with the highest negative inductive effect enhanced dimorphic mesophases, as well as $\mathrm{N}$ and smA. However, the SmA phase of the fluoro-substituted complex was the most stable among the halogen candidates bearing an octyloxy terminal group (the observed SmA range was $22.8^{\circ} \mathrm{C}$ ). The highly parallel interaction, which could be promoted by the fluorine atom, could be responsible for the enhanced smectic mesophase and the moderate total mesophase range $\left(37.3^{\circ} \mathrm{C}\right)$. The attachment of the nitro group increased the $\pi-\pi$ loop to consolidate the SmA and $\mathrm{N}$ mesophases. The reported SmA and $\mathrm{N}$ mesophase ranges were 23.7 and $34.9{ }^{\circ} \mathrm{C}$, respectively, which corresponded to a relatively broad total mesomorphic temperature range $\left(58.6^{\circ} \mathrm{C}\right)$.

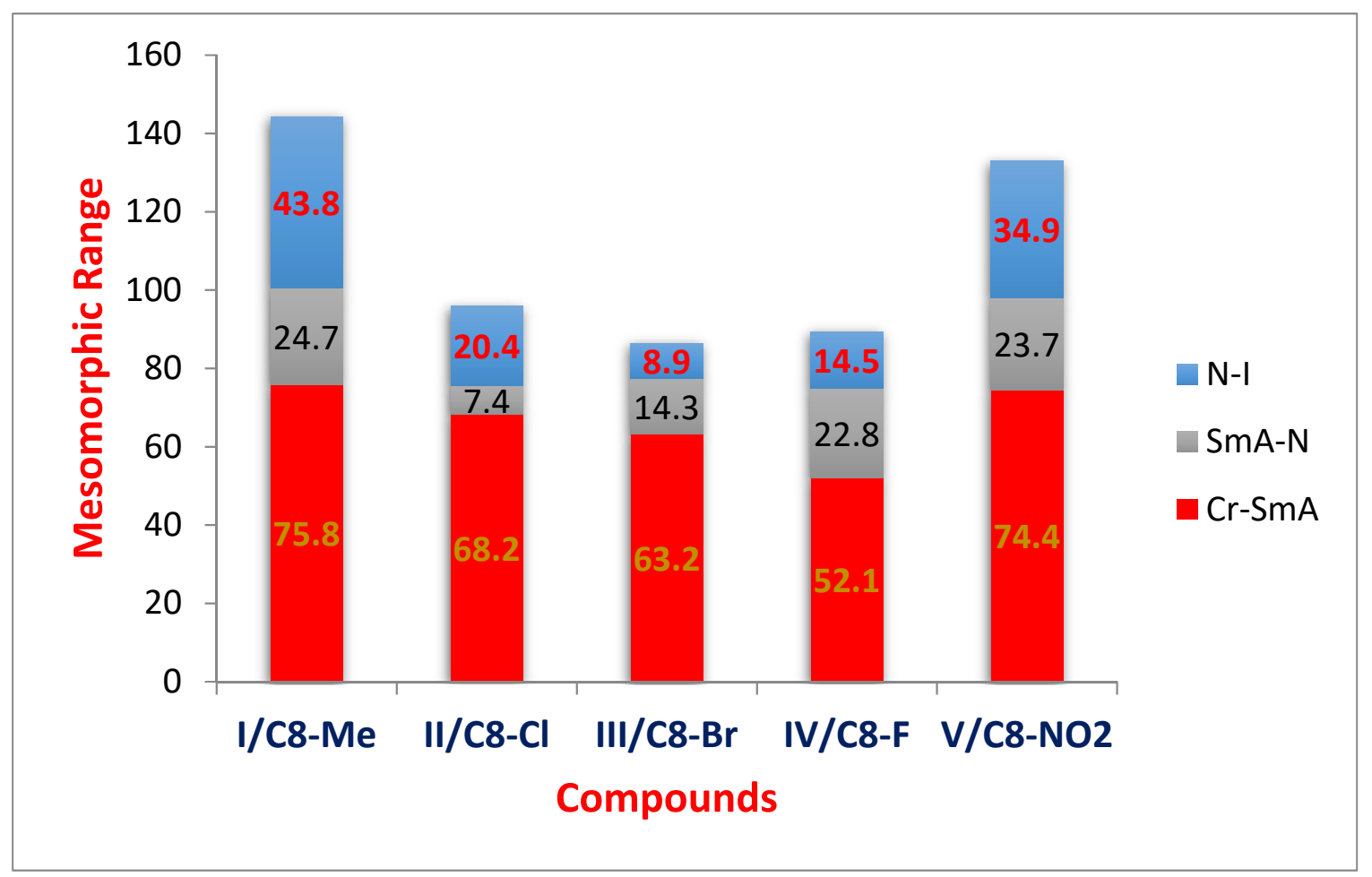

Figure 3. The relationship between the attached polar group and the transition temperatures. 


\subsection{Theoretical Calculations (DFT) \\ Molecular Geometry}

Recently, we employed theoretical calculations to correlate experimental ones regarding liquid crystalline materials [62-73]. Thus, DFT calculations were conducted for the basis set, B3LYP 6-311g (d, p), for all the supramolecular analogous series of the complexes that were prepared with p-octyloxy benzoic acid $((\mathbf{I}-\mathbf{V})$ C8). B3LYP level with the 6-311G $(\mathrm{d}$, p) basis set is reasonable for molecular investigation of liquid crystalline materials [74-77]. The optimized geometrical structures of the investigated compounds were measured in the gas phase, employing Gaussian 9. To determine the lowest-energy geometries, structural optimization was employed to optimize all the compounds. This optimization method was applied to determine the geometrical structures of the lowest energy conformations of the compounds until a new lowest-energy geometrical structure, which is known as the convergence, was generated. Thereafter, the optimized structures were employed to measure the frequency and several significant thermodynamic parameters. The optimized molecular structures of the compounds were stable because of the absence of an imaginary frequency, as shown in Figure 4. Further, the non-coplanar structures (with a bent shape due to lateral hydrogen bonding and the twist angle of the Schiff base) of the pyridine $\mathrm{CH}=\mathrm{N}$ bond were determined as the approximate molecular geometry. This twist angle was clearly influenced by the duration and electronic existence of the polar groups, as well as the degree of the extra conjugation in the structure. The highly electron-withdrawing nitro group of the V/C8 derivative exhibited the highest bent-shape angle between the acid and pyridine ring $\left(Q=129.1^{\circ}\right)$, which could be demonstrated regarding the electron attraction ability of the nitro group, which also decreased the strength of hydrogen bonding (the length of the hydrogen bond was $1.655 \AA$ ). Conversely, Compound IV/C8 bearing the compact fluorine atom possessed a bent-shape angle of $Q=127.7^{\circ}$ : the larger the halide atom, the larger the reported bent angle $\left(Q=128.2^{\circ}\right.$ and $128.9^{\circ}$ for the chloro and bromo derivatives, respectively).
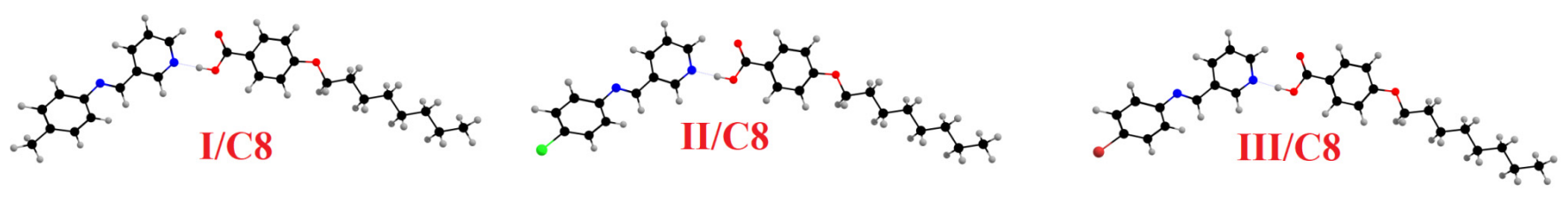

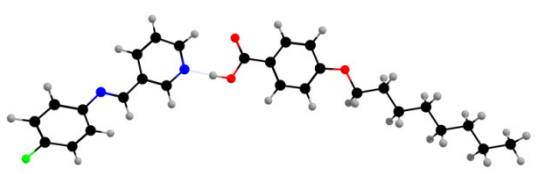

$\mathrm{IV} / \mathrm{C} 8$

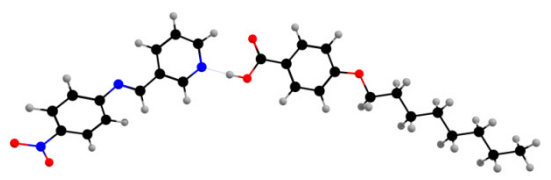

$\mathrm{V} / \mathrm{C} 8$

Figure 4. The calculated molecular geometry of the prepared supramolecular para-octyloxy benzoic acid complexes ((I-V)C8), H (gray), C (black), N (blue) and O (red). 2.3. Frontier Molecular Orbitals (FMO) and Polarizability.

This finding could be further interpreted regarding the strength of the hydrogen bond, where both halides possessed the same hydrogen bond length (1.63 $⿱$ ). Contrarily, the hyperconjugated Me group possessed the least hydrogen bond length (1.628 $\AA$ ). This result could be explained in relation to the increased electron density in the nitrogen atom caused by the positive electron inductive effect of the Me group. Although these theoretical molecular geometries might rationally predict the preferred molecular structure in the gas phase, the presence of these compounds in the condensed phases of the liquid crystalline matter, which possessed a different lowest energy, and more elongated species were preferred [78]. Furthermore, the lengths of the flexible alkoxy terminal groups considerably impacted the mesomorphic behaviors. The stabilities and types of the enhanced liquid crystalline phases were significantly influenced by the length of the alkoxy group, and this was generally explained by the molecular shape [66]. 
Table 2 and Figure 5 present the expected plots of FMOs (highest occupied MO (HOMO) and lowest unoccupied MO (LUMO)) of the prepared compounds, (I-V)C8. Figure 6 reveals that the electron densities of the sites, which were involved in the formations of LUMOs, as well as the aromatic ring of alkoxybenzoic acid, which was involved in the formation of HOMOs, were localized on the pyridyl component. Conversely, the electron densities of FMOs were unaffected by the polar groups. Moreover, the presence of the polar groups exerted a major impact on the energy gap of FMOs. The FMO levels were affected by the attachment of the polar groups. Conversely, the V/C8 nitro derivative exerted the same effect. Dissimilar to the other groups, the addition of an electron to the withdrawing $\mathrm{NO}_{2}$ group reduced the HOMO and LUMO levels. The energy difference was minimized by the extra-conjugated nitro group. The co-planarity of the nitro group increased and caused an extra conjugation of the aromatic rings and a decrease in the energy gap of FMOs.

Table 2. FMO Energies (eV) and their values for the prepared para-octyloxy benzoic acid supramolecular complexes $(\mathbf{I}-\mathbf{V}) \mathbf{C 8}$.

\begin{tabular}{cccc}
\hline Compounds & HOMO & LUMO & $\Delta \mathrm{E}$ \\
\hline I/C8 & -6.11 & -2.33 & 3.78 \\
\hline II/C8 & -6.18 & -2.61 & 3.57 \\
\hline III/C8 & -6.17 & -2.57 & 3.60 \\
\hline IV/C8 & -6.17 & -2.54 & 3.63 \\
\hline V/C8 & -6.26 & -3.35 & 2.91 \\
\hline
\end{tabular}
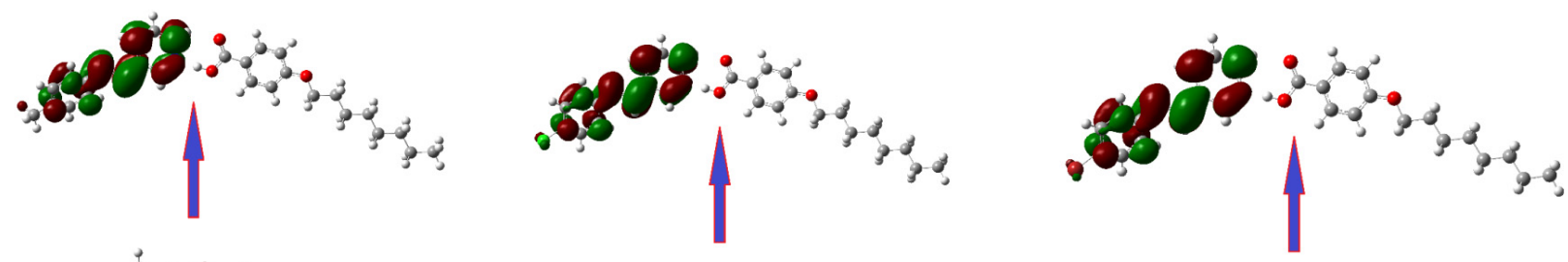

LUMO
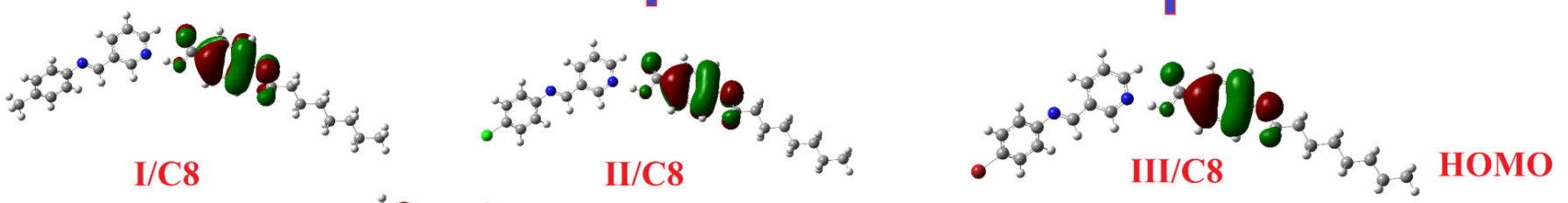

I/C8
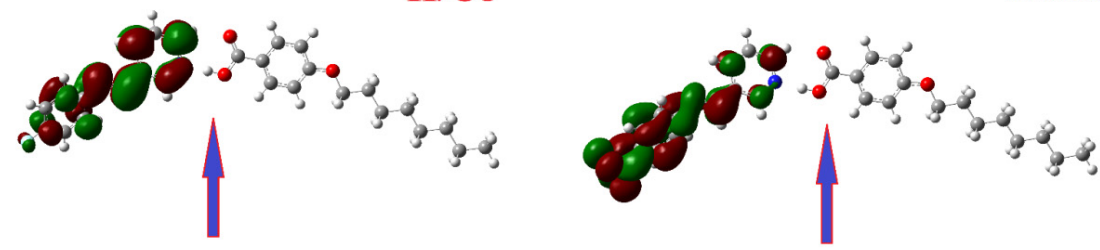

LUMO
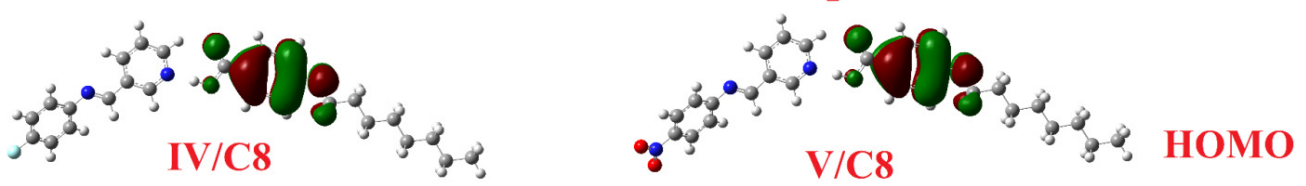

Figure 5. The calculated plots for the para-octyloxy benzoic acid supramolecular complexes, (I-V)C8, frontier molecular orbitals, H (gray), C (black), N (blue) and O (red). 


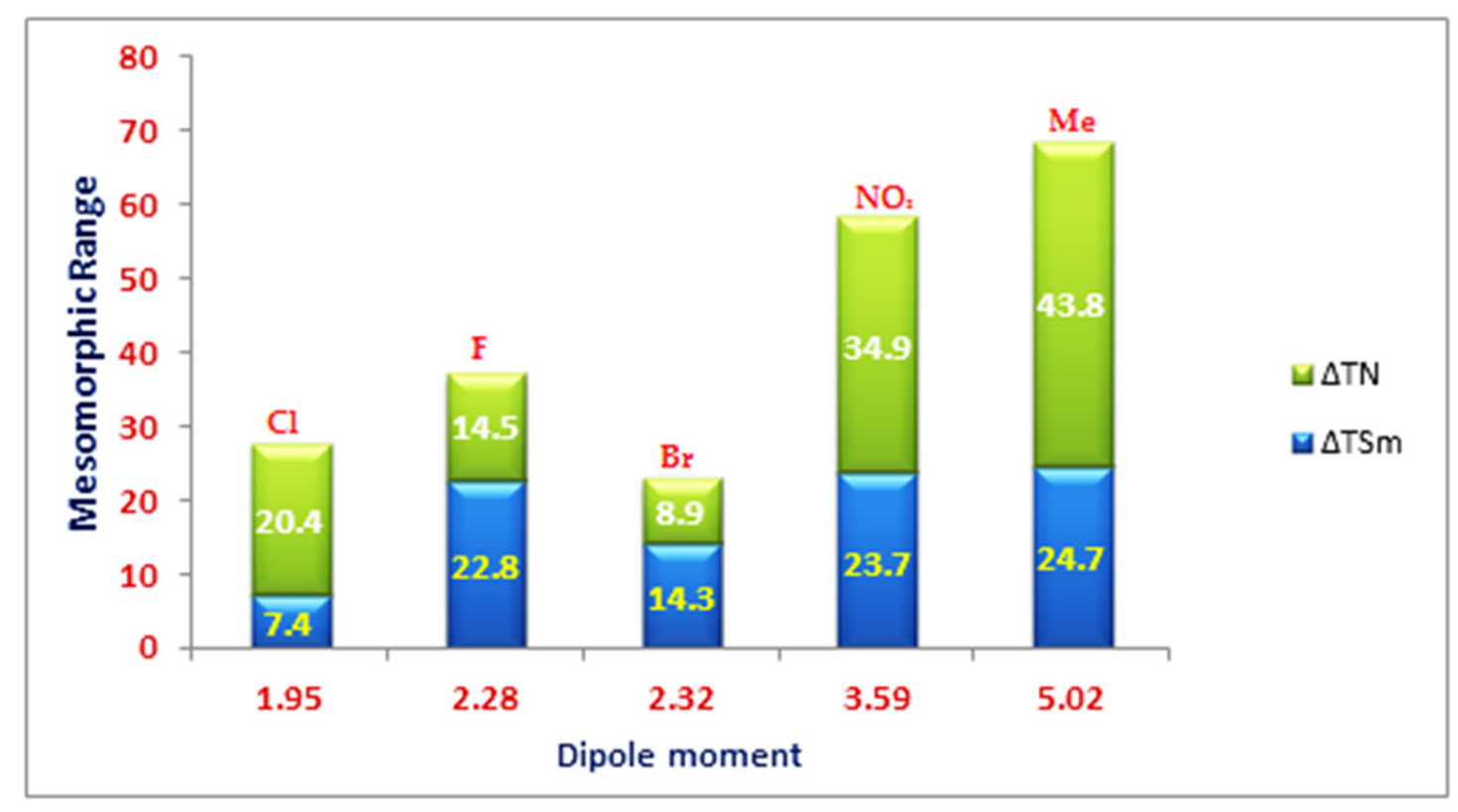

Figure 6. Dependence of the mesomorphic range with the calculated dipole moment.

Figure 6 shows the $T$ of the analogous series of the C8 chain length as a function of the measured dipole moment. A high dipole moment corresponded to the highest electron-withdrawing $\mathrm{NO}_{2}$ group, and the hyperconjugated Me groups, I/C8 and V/C8, clearly induced the nematic and smectic ranges, respectively. This finding may be clarified by the enhancement of the parallel intermolecular interactions, which facilitated a high degree of ordering in the molecules in the smectic mesophase. Conversely, enhancement of the smectic mesophase might be caused by the high dipole moment that was associated with the small compact fluorine group. Although there was a slight difference between the measured dipole moments of $\mathrm{Cl}$ and $\mathrm{Br}$, there was a significant difference between the smectic mesophase ranges of II/C8 $\left(7.4^{\circ} \mathrm{C}\right)$ and III/C8 $\left(22.8^{\circ} \mathrm{C}\right)$, probably owing to the higher resonance effect of the $\mathrm{Br}$ atom compared with that of $\mathrm{Cl}$, which increased the $\pi$-loop, thus enhancing the side-side interactions (see Supplementary data Tables S1 and S2).

Figure 7 reveals the effect of polarizability on Ts of the analogous series, (I-V)C8. The increases in the polarizabilities evidently reduced the total mesomorphic range (except that of the highly electron-withdrawing nitro group). This could be elucidated regarding the co-effectiveness of other factors, such as the dipole moment of the overall behavior. However, regarding the halides, the increase in the polarizability successfully reduced the nematic and smectic mesophase ranges.

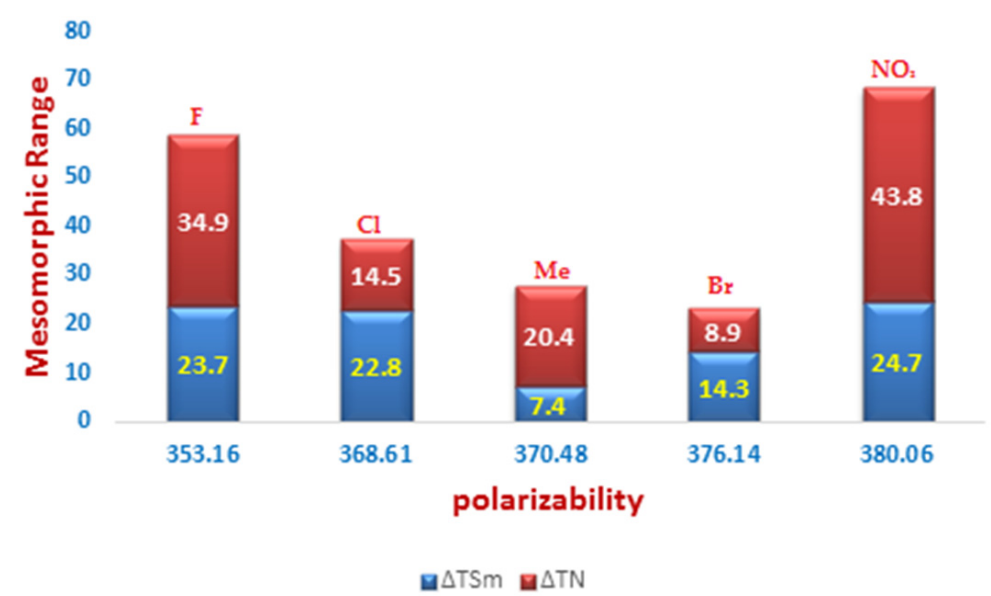

Figure 7. Dependence of the mesomorphic range with the calculated polarizability. 
Figure 8 shows the relationship of calculated aspect ratios and mesophase range for the $\mathbf{C} 8$ and $\mathbf{C 1 6}$ analogous series, $(\mathrm{I}-\mathrm{V}) \mathbf{C} 8$ and $(\mathrm{I}-\mathrm{V}) \mathrm{C} 16$. The variation of the aspect ratio with respect to the chain length is not systematic either for the smectic or the nematic mesophase ranges. This result could be illustrated in terms of the accumulative effects of other factors such as the dipole moment, polarizability, etc., that could act together to show the enhanced mesophase range.
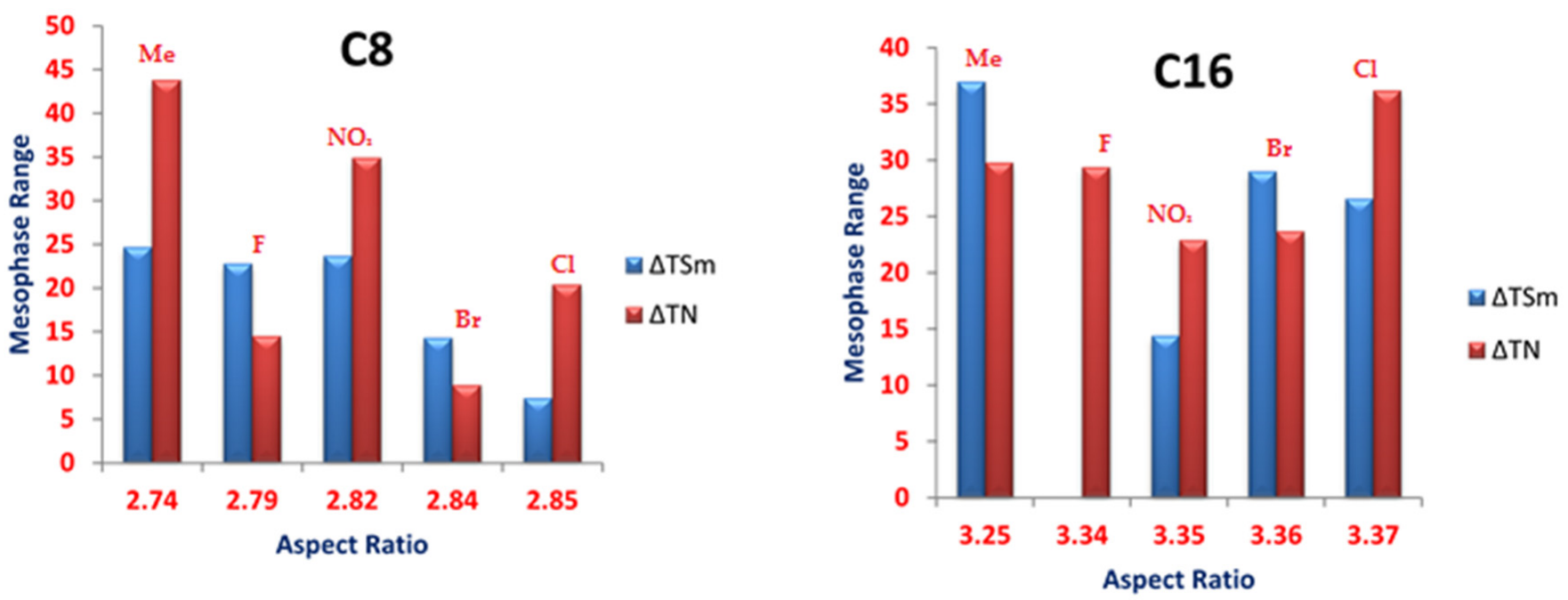

Figure 8. Dependence of the mesomorphic range with the calculated aspect ratios.

\subsection{Molecular Electrostatic Potential (MEP)}

The charge-distribution map of the prepared para-octyloxy benzoic acid-derived supramolecular complexes (I-V)C8 was calculated by the same approach employing the same basis sets according to MEP (Figure 9). The hydrogen-bonded component of the supramolecular complexes was assumed to be located in the region where the negatively charged atomic sites (the red region) were concentrated. However, it was predicted that the alkoxy chain moieties possessed the least negatively charged atomic sites regardless of the composition of the attached polar groups (the blue regions). The predicted chargedistribution maps might indicate the formation of the LC-enhanced mesophase.
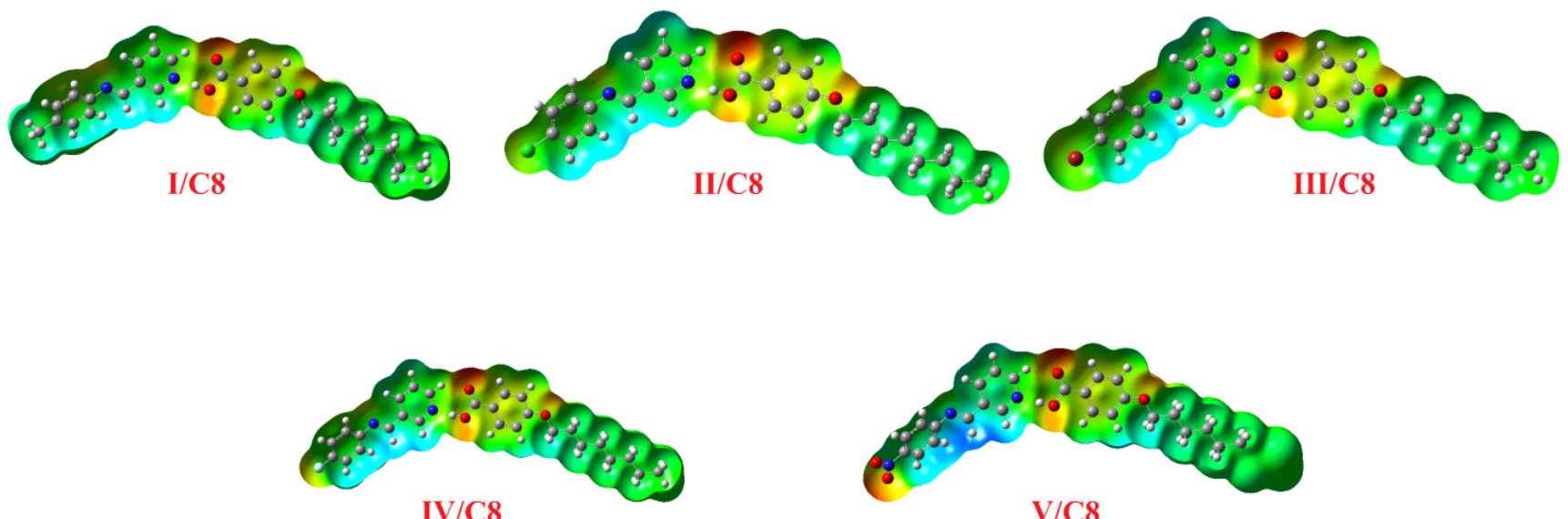

$\mathrm{V} / \mathrm{C} 8$

Figure 9. Molecular electrostatic potentials (MEP) for the para-octyloxy benzoic acid C8 supramolecular complexes prepared, (I-V)C8, H (gray), C (black), N (blue) and O (red). 


\section{Materials and Methods}

All the chemicals ( $>98 \%$ pure) were purchased from TCI Company, Japan. The Schiff bases were prepared and recrystallized two times from an ethanol/water mixture, after which their purities were confirmed by thin-layer chromatography (TLC) (Scheme 1). Finally, the supramolecular complexes were prepared by mixing equimolar ratios of a particular Schiff base with para-alkoxy benzoic acid, followed by melting to ensure the formation of the complexes (Scheme 2).

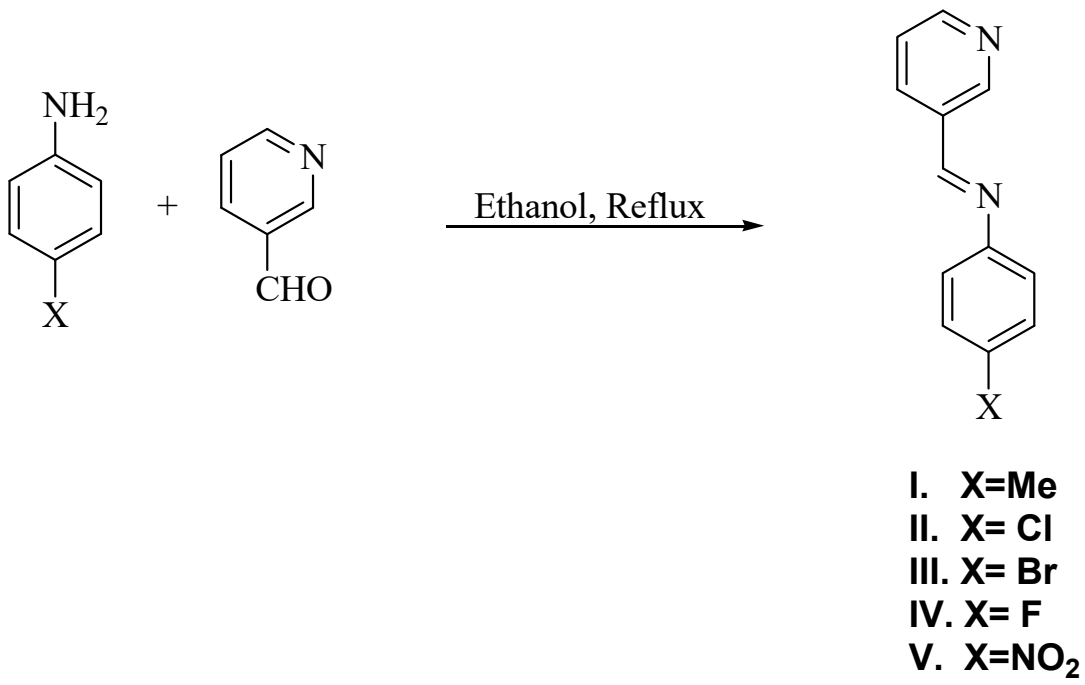

Scheme 1. Schiff bases (I-V) preparation.

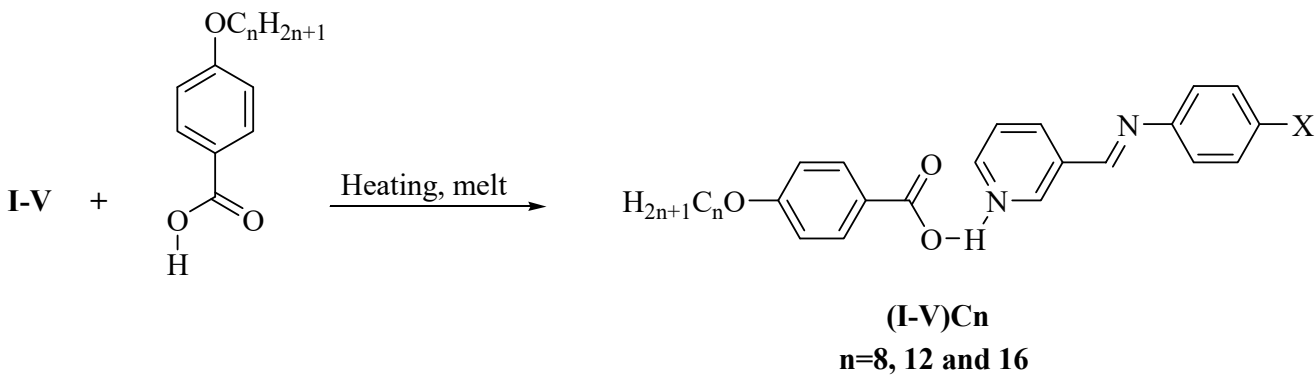

Scheme 2. Preparation of the complexes [(I-V)Cn].

The FT-IR spectra were recorded on a spectrometer (Shimadzu, model: IRAffinity, Japan). The samples were prepared as KBr pellets.

The phase changes in the materials were determined by DSC employing a calorimeter (Shimadzu DSC-60A, Japan). The specimens (2-3 mg) were encapsulated in aluminum pans and heated or cooled in a dry nitrogen atmosphere. The measurements were performed at a heating rate of $10.0^{\circ} \mathrm{C} / \mathrm{min}$. Further, the samples were heated from room temperature to $150{ }^{\circ} \mathrm{C}$ and cooled back to room temperature at the same heating rate. Finally, the samples were reheated to $180^{\circ} \mathrm{C}$ (the heating programs were conducted in an inert atmosphere (nitrogen gas). The accuracy of the temperature monitoring was $<1.0^{\circ} \mathrm{C}$. The types of different mesophase textures were characterized using standard polarized optical microscope (POM, Wild, Germany).

\section{Conclusions}

Novel supramolecular three-ring Schiff base LC complexes were prepared and investigated. The prepared systems were designed so that the lengths of the alkoxy chain varied from eight to sixteen carbons on one side, while the terminal small groups that substituted the aniline ring exhibited different polarities. The hydrogen bonding inter- 
action was verified by FT-IR spectroscopy by different approaches, especially through the existence of the three Fermi peaks. The mesomorphic thermal and optical characteristics of the samples indicated that they were dimorphic regardless of the small compact polar groups or the alkoxy chain lengths (except for the C16-Cl complex, which was monomorphic). The results reveal that the polarities of the two compact polar groups, as well as the lengths of the alkoxy chains, strongly affected the mesomorphic characteristics and thermal stabilities of the mesophases of the supramolecular complexes. Interestingly, the observed values of $\Delta \mathrm{Hs}$ coupled with the crystalline mesomorphic transitions were significantly small $(1.12-5.07 \mathrm{~kJ} / \mathrm{mol})$, thereby indicating weak hydrogen bonding in the crystalline solid-formed complexes, contrary to the values in the literature for crystalline mesomorphic transitions $(20-100 \mathrm{~kJ} / \mathrm{mol})$. However, $\Delta \mathrm{Hs}$, which corresponded to the mesomorphic-isotropic transitions, varied from 0.06 to 9.54 depending on the polarity of the small compact para-groups that were attached to the aniline moiety. The incorporation of the compact fluorine atom exerting the highest negative inductive effect promoted the formation of the SmA mesophase. The enhanced SmA mesophase in the fluoro derivatives compared with those of the other halogen-substituted candidates might be caused by the highly parallel interaction that was probably promoted by the attachment of the fluorine atom to increase the overall mesophase range $\left(37.3^{\circ} \mathrm{C}\right)$. The results indicate that the nematic mesophase range of the Me complexes decreased as the length of the terminal alkoxy chain increased with the enhancement of the stability of the SmA mesophase. This decrease in the nematic range could be attributed to the increased terminal association of the alkoxy chain, which facilitated the enhanced backing of the molecules. Finally, DFT calculations were discussed and the polar groups' effect on the calculated parameters and the mesomorphic behavior was illustrated. The DFT geometrical structures revealed non-coplanar structures with a bent shape due to lateral hydrogen bonding and the twist angle of the Schiff base. The mesomorphic range is affected by the polar attached group in terms of the dipole moment, polarizability and the aspect ratio change.

Supplementary Materials: The following are available online at https:/ /www.mdpi.com/article/10 $.3390 /$ cryst11060628/s1, Table S1: Calculated dipole moment (Debye), polarizability $\left(\mathrm{Bohr}^{3}\right)$ of the supramolecular complexes of para-octyloxy benzoic acid [(I-V)C8]; Table S2: Mesomorphic parameters and aspect ratios of supramolecular complexes of para-octyloxy benzoic acid [(I-V)C8,C16].

Author Contributions: Conceptualization, S.Z.M.; methodology, S.Z.M.; software, M.H.; validation, S.Z.M. and M.H.; formal analysis, S.Z.M. and M.H.; investigation, S.Z.M.; resources, S.Z.M.; data curation, S.Z.M. and D.M.A.; writing—original draft preparation, S.Z.M. and M.H.; writing-review and editing, S.Z.M. and D.M.A.; visualization, S.Z.M.; supervision, S.Z.M.; project administration, S.Z.M.; funding acquisition, S.Z.M. All authors have read and agreed to the published version of the manuscript.

Funding: This research was funded by Deanship of Scientific Research at King Saud University for funding this work through the research group number (RG-1440-143).

Institutional Review Board Statement: Not applicable.

Informed Consent Statement: Not applicable.

Data Availability Statement: Not applicable.

Acknowledgments: The authors extend their appreciation to the Deanship of Scientific Research at King Saud University for funding this work through the research group number (RG-1440-143).

Conflicts of Interest: The authors declare no conflict of interest.

\section{References}

1. Arunan, E.; Desiraju, G.R.; Klein, R.A.; Sadlej, J.; Scheiner, S.; Alkorta, I.; Clary, D.C.; Crabtree, R.H.; Dannenberg, J.J.; Hobza, P. Defining the hydrogen bond: An account (IUPAC Technical Report). Pure Appl. Chem. 2011, 83, 1619-1636. [CrossRef]

2. Shimizu, K.; Ferreira da Silva, J. Halogen and hydrogen bonding interplay in the crystal packing of halometallocenes. Molecules 2018, 23, 2959. [CrossRef] 
3. Borissova, A.O.; Antipin, M.Y.; Perekalin, D.S.; Lyssenko, K.A. Crucial role of Ru $\cdots H$ interactions in the crystal packing of ruthenocene and its derivatives. CrystEngComm 2008, 10, 827-832. [CrossRef]

4. Park, J.H.; Kim, K.H.; Park, Y.W.; Lagerwall, J.P.; Scalia, G. Ultralong ordered nanowires from the concerted self-assembly of discotic liquid crystal and solvent molecules. Langmuir 2015, 31, 9432-9440. [CrossRef]

5. Alnoman, R.B.; Ahmed, H.A.; Hagar, M.; Abu Al-Ola, K.A.; Alrefay, B.S.; Haddad, B.A.; Albalawi, R.F.; Aljuhani, R.H.; Aloqebi, L.D.; Alsenani, S.F. Induced phases of new H-bonded supramolecular liquid crystal complexes; mesomorphic and geometrical estimation. Molecules 2020, 25, 1549. [CrossRef]

6. Scholte, A.; Hauche, S.; Wagner, M.; Prehm, M.; Poppe, S.; Chen, C.; Liu, F.; Zeng, X.; Ungar, G.; Tschierske, C. A self-assembled liquid crystal honeycomb of highly stretched (3-1-1)-hexagons. Chem. Commun. 2020, 56, 62-65. [CrossRef]

7. Sun, H.-J.; Zhang, S.; Percec, V. From structure to function via complex supramolecular dendrimer systems. Chem. Soc. Rev. 2015, 44, 3900-3923. [CrossRef]

8. Chen, X.; Chen, L.; Yao, K.; Chen, Y. Self-assembly of diblock polythiophenes with discotic liquid crystals on side chains for the formation of a highly ordered nanowire morphology. ACS Appl. Mater. Interfaces 2013, 5, 8321-8328. [CrossRef] [PubMed]

9. Guan, S.; Wen, W.; Yang, Z.; Chen, A. Liquid Crystalline Nanowires by Polymerization Induced Hierarchical Self-Assembly. Macromolecules 2019, 53, 465-472. [CrossRef]

10. Chen, J.-W.; Huang, C.-C.; Chao, C.-Y. Supramolecular liquid-crystal gels formed by polyfluorene-based $\pi$-conjugated polymer for switchable anisotropic scattering device. ACS Appl. Mater. Interfaces 2014, 6, 6757-6764. [CrossRef]

11. Foelen, Y.; van der Heijden, D.A.; Del Pozo, M.; Lub, J.; Bastiaansen, C.W.; Schenning, A.P. An Optical Steam Sterilization Sensor Based On a Dual-Responsive Supramolecular Cross-Linked Photonic Polymer. ACS Appl. Mater. Interfaces 2020, 12, 16896-16902. [CrossRef]

12. Todisco, M.; Fraccia, T.P.; Smith, G.P.; Corno, A.; Bethge, L.; Klussmann, S.; Paraboschi, E.M.; Asselta, R.; Colombo, D.; Zanchetta, G. Nonenzymatic polymerization into long linear RNA templated by liquid crystal self-assembly. ACS Nano 2018, 12, 9750-9762. [CrossRef] [PubMed]

13. Pauling, L. The nature of the chemical bond. II. The one-electron bond and the three-electron bond. J. Am. Chem. Soc. 1931, 53, 3225-3237. [CrossRef]

14. Steiner, T.; Saenger, W. Role of $\mathrm{CH}$. cntdot.. cntdot.. cntdot. O hydrogen bonds in the coordination of water molecules. Analysis of neutron diffraction data. J. Am. Chem. Soc. 1993, 115, 4540-4547. [CrossRef]

15. Watt, S.W.; Dai, C.; Scott, A.J.; Burke, J.M.; Thomas, R.L.; Collings, J.C.; Viney, C.; Clegg, W.; Marder, T.B. Structure and Phase Behavior of a 2: 1 Complex between Arene-and Fluoroarene-Based Conjugated Rigid Rods. Angew. Chem. Int. Ed. 2004, 43, 3061-3063. [CrossRef]

16. Arikainen, E.O.; Boden, N.; Bushby, R.J.; Lozman, O.R.; Vinter, J.G.; Wood, A. Complimentary polytopic interactions. Angezw. Chem. 2000, 112, 2423-2426. [CrossRef]

17. Lozman, O.R.; Bushby, R.J.; Vinter, J.G. Complementary polytopic interactions (CPI) as revealed by molecular modelling using the XED force field. J. Chem. Soc. Perkin Trans. 2001, 2, 1446-1452. [CrossRef]

18. Kato, T.; Frechet, J.M. A new approach to mesophase stabilization through hydrogen bonding molecular interactions in binary mixtures. J. Am. Chem. Soc. 1989, 111, 8533-8534. [CrossRef]

19. Nakazawa, T.; Ishihara, M.; Yamaguchi, M.; Sugihara, Y.; Murata, I. Synthesis and Properties of 3-Substituted 8 H-3-Azaheptalen8-ones. Chem. Lett. 1990, 19, 91-92. [CrossRef]

20. Kato, T.; Mizoshita, N.; Kanie, K. Hydrogen-bonded liquid crystalline materials: Supramolecular polymeric assembly and the induction of dynamic function. Macromol. Rapid Commun. 2001, 22, 797-814. [CrossRef]

21. Nguyen, H.L.; Horton, P.N.; Hursthouse, M.B.; Legon, A.C.; Bruce, D.W. Halogen bonding: A new interaction for liquid crystal formation. J. Am. Chem. Soc. 2004, 126, 16-17. [CrossRef]

22. Price, D.J.; Willis, K.; Richardson, T.; Ungar, G.; Bruce, D.W. Hydrogen bonded liquid crystals from nitrophenols and alkoxystilbazoles. J. Mater. Chem. 1997, 7, 883-891. [CrossRef]

23. Treybig, A.; Eissflog, W.W.; Plass, M.; Kresse, H. Hydrogen-bond induced liquid crystalline phases in compounds with a carbonyl group as proton acceptor. Mol. Cryst. Liq. Cryst. Sci. Technol. Sect. A Mol. Cryst. Liq. Cryst. 1997, 300, 127-141. [CrossRef]

24. Sideratou, Z.; Tsiourvas, D.; Paleos, C.; Skoulios, A. Liquid crystalline behaviour of hydrogen bonded complexes of a nonmesogenic anil with pn-alkoxybenzoic acids. Liq. Cryst. 1997, 22, 51-60. [CrossRef]

25. Lin, H.-C.; Ko, C.-W.; Guo, K.; Cheng, T.-W. Supramolecular liquid crystals containing isoquinoline hydrogen-bonded acceptors. Liq. Cryst. 1999, 26, 613-618. [CrossRef]

26. Demus, D.; Goodby, J.W.; Gray, G.W.; Spiess, H.W.; Vill, V. Handbook of Liquid Crystals, Volume 2A: Low Molecular Weight Liquid Crystals I: Calamitic Liquid Crystals; John Wiley \& Sons: Hoboken, NJ, USA, 2011.

27. Torgova, S.I.; Strigazzi, A. Hydrogen bonding and its role in the liquid crystal formation and properties. Mol. Cryst. Liq. Cryst. Sci. Technol. Sect. A Mol. Cryst. Liq. Cryst. 1999, 336, 229-245. [CrossRef]

28. Tal'roze, R.; Shatalova, A.; Shandryuk, G. Development and stabilization of liquid crystalline phases in hydrogen-bonded systems. Polym. Sci. Ser. B 2009, 51, 57-83. [CrossRef]

29. He, W.-L.; Wang, L.; Yang, Z.; Yang, H.; Xie, M.-W. Synthesis and optical behaviour of hydrogen-bonded liquid crystals based on a chiral pyridine derivative. Liq. Cryst. 2011, 38, 1217-1225. [CrossRef] 
30. Muniprasad, M.; Srinivasulu, M.; Chalapathi, P.; Potukuchi, D. Influence of chemical moieties and the flexible chain for the tilted smectic phases in linear hydrogen bonded liquid crystals with Schiff based pyridene derivatives. J. Mol. Struct. 2012, 1015, 181-191. [CrossRef]

31. Pai, P.; Kulkarni, S.D.; Srinivasulu, M.; Baral, M.; Apoorva, M.; Bhagavath, P. Enhanced conductivity in nanoparticle doped hydrogen bonded binary mixture. J. Mol. Liq. 2019, 296, 111754. [CrossRef]

32. Wei, Q.; Guo, X.; Yang, H. Synthesis and mesomorphic properties of two series of hydrogen-bonded liquid crystals based on laterally fluorinated benzoic acid and 4, 4'-bipyridine with a molar ratio of 2:1. Mol. Cryst. Liq. Cryst. 2012, 557, 1-10. [CrossRef]

33. Miranda, M.D.; Chávez, F.V.; Maria, T.M.; Eusebio, M.E.S.; Sebastião, P.; Silva, M.R. Self-assembled liquid crystals by hydrogen bonding between bipyridyl and alkylbenzoic acids: Solvent-free synthesis by mechanochemistry. Liq. Cryst. 2014, 41, 1743-1751 [CrossRef]

34. Naoum, M.M.; Fahmi, A.A.; Mohammady, S.Z.; Abaza, A.H. Effect of lateral substitution on supramolecular liquid crystal associates induced by hydrogen-bonding interactions between $4-\left(4^{\prime}\right.$-pyridylazo-3-methylphenyl)- $4^{\prime \prime}$-alkoxy benzoates and 4-substituted benzoic acids. Liq. Cryst. 2010, 37, 475-486. [CrossRef]

35. Voutsas, E.C.; Boulougouris, G.C.; Economou, I.G.; Tassios, D.P. Water/hydrocarbon phase equilibria using the thermodynamic perturbation theory. Ind. Eng. Chem. Res. 2000, 39, 797-804. [CrossRef]

36. Thote, A.J.; Gupta, R.B. Hydrogen-bonding effects in liquid crystals for application to LCDs. Ind. Eng. Chem. Res. 2003, 42, 1129-1136. [CrossRef]

37. Crisp, G.T.; Jiang, Y.-L. Intramolecular hydrogen bonding of nucleobases. Tetrahedron Lett. 2002, 43, 3157-3160. [CrossRef]

38. Lammers, J.N. Phase behavior of glycol in gas pipeline calculated. Oil Gas J. 1991, 89, 15.

39. Kataoka, H.; Shigeno, N.; Munakata, M.; Urabe, T. Reflective Guest-Host Liquid-Crystal Display Device. U.S. Patent 6016178A, 18 January 2000.

40. Matsude, M. Reflective Liquid Crystal Display Device Having Nematic Liquid Crystal and Dichroic Dye. Japanese Patent JP 19564, 2000.

41. Acree, W.E., Jr.; Chickos, J.S. Phase change enthalpies and entropies of liquid crystals. J. Phys. Chem. Ref. Data 2006, 35, 1051-1330. [CrossRef]

42. Oweimreen, G.; Morsy, M. DSC studies on p-cyanophenyl p-(n-alkyl) benzoate liquid crystals: Evidence for polymorphism and conformational change. Thermochim. Acta 1999, 325, 111-118. [CrossRef]

43. Domalski, E.S.; Hearing, E.D. Heat capacities and entropies of organic compounds in the condensed phase. Volume III. J. Phys. Chem. Ref. Data 1996, 25, 1-525. [CrossRef]

44. Oweimreen, G.; Morsy, M. DSC studies on p-(n-alkyl)-p'-cyanobiphenyl (RCB's) and p-(n-alkoxy)-p'-cyanobiphenyl (ROCB's) liquid crystals. Thermochim. Acta 2000, 346, 37-47. [CrossRef]

45. Yousif, Y.Z.; Al-hamdani, A.J. Liquid-crystalline behaviour of some bis (4-alkyloxyphenyl) thiazolo [5,4-d] dithiazoles. Liq. Cryst. 1993, 15, 451-460. [CrossRef]

46. Tsuji, K.; Sorai, M.; Suga, H.; Seki, S. Heat Capacity and Thermodynamic Properties of p'-Substituted p-n-Hexyloxybenzylideneaniline. I. p-n-Hexyloxybenzylideneamno-p'-Benzonitrile (HBAB). Mol. Cryst. Liq. Cryst. 1979, 55, 71-88. [CrossRef]

47. Chidichimo, G.; Salerno, G.; Veltri, L.; Gabriele, B.; Nicoletta, F.P. Synthesis and mesomorphic properties of new liquid crystalline stilbene derivatives containing vinyloxyalkoxy chains. Liq. Cryst. 2004, 31, 733-737. [CrossRef]

48. Wang, X.; Cui, W.; Li, B.; Zhang, X.; Zhang, Y.; Huang, Y. Supramolecular self-assembly of two-component systems comprising aromatic amides/Schiff base and tartaric acid. Front. Chem. Sci. Eng. 2020, 14, 1112-1121. [CrossRef]

49. Cramer, J.; Jiang, X.; Schönemann, W.; Silbermann, M.; Zihlmann, P.; Siegrist, S.; Fiege, B.; Jakob, R.P.; Rabbani, S.; Maier, T. Enhancing the enthalpic contribution of hydrogen bonds by solvent shielding. RSC Chem. Biol. 2020, 1, 281-287. [CrossRef]

50. Huang, Y.; Zhang, X.; Cui, W.; Wang, X.; Li, B.; Zhang, Y.; Yang, J. Novel liquid crystalline organogelators based on terephthalic acid and terephthalaldehyde derivatives: Properties and promotion through the formation of halogen bonding. New J. Chem. 2020, 44, 614-625. [CrossRef]

51. Du, M.; Li, L.; Zhang, J.; Li, K.; Cao, M.; Mo, L.; Hu, G.; Chen, Y.; Yu, H.; Yang, H. Photoresponsive iodine-bonded liquid crystals based on azopyridine derivatives with a low phase-transition temperature. Liq. Cryst. 2019, 46, 37-44. [CrossRef]

52. Saunders, M.; Hyne, J.B. Study of hydrogen bonding in systems of hydroxylic compounds in carbon tetrachloride through the use of NMR. J. Chem. Phys. 1958, 29, 1319-1323. [CrossRef]

53. Hu, Y.; Shim, Y.; Oh, J.; Park, S.; Park, S.; Ishii, Y. Synthesis of ${ }^{13} \mathrm{C}-1,{ }^{15} \mathrm{~N}$-labeled graphitic carbon nitrides and NMR-based evidence of hydrogen-bonding assisted two-dimensional assembly. Chem. Mater. 2017, 29, 5080-5089. [CrossRef]

54. Lam, R.K.; Smith, J.W.; Saykally, R.J. Communication: Hydrogen Bonding Interactions in Water-Alcohol Mixtures from X-ray Absorption Spectroscopy; AIP Publishing LLC: Melville, NY, USA, 2016.

55. Pothoczki, S.; Pethes, I.; Pusztai, L.; Temleitner, L.; Csókás, D.; Kohara, S.; Ohara, K.; Bakó, I. Hydrogen bonding and percolation in propan-2-ol-water liquid mixtures: X-ray diffraction experiments and computer simulations. arXiv 2020, arXiv:2001.11923.

56. Martinez-Felipe, A.; Cook, A.G.; Abberley, J.P.; Walker, R.; Storey, J.M.; Imrie, C.T. An FT-IR spectroscopic study of the role of hydrogen bonding in the formation of liquid crystallinity for mixtures containing bipyridines and 4-pentoxybenzoic acid. RSC Adv. 2016, 6, 108164-108179. [CrossRef]

57. Martínez-Felipe, A.; Imrie, C.T. The role of hydrogen bonding in the phase behaviour of supramolecular liquid crystal dimers. J. Mol. Struct. 2015, 1100, 429-437. [CrossRef] 
58. Paterson, D.A.; Martínez-Felipe, A.; Jansze, S.M.; Marcelis, A.T.M.; Storey, J.M.D.; Imrie, C.T. New insights into the liquid crystal behaviour of hydrogen-bonded mixtures provided by temperature-dependent FTIR spectroscopy. Liq. Cryst. 2015, 42, 928-939. [CrossRef]

59. Sherif, S.; Nafee, H.A.A. Mohamed Hagar New architectures of supramolecular H-bonded liquid crystal complexes based on dipyridine Derivatives. Liq. Cryst. 2020, 1-12. [CrossRef]

60. Alhaddad, O.; Ahmed, H.; Hagar, M. Experimental and Theoretical Approaches of New Nematogenic Chair Architectures of Supramolecular H-Bonded Liquid Crystals. Molecules 2020, 25, 365. [CrossRef] [PubMed]

61. Babkov, L.; Korolevich, M.; Moiseikina, E. Hydrogen bonding, IR spectrum, and the structure of methyl- $\beta$-D-glucopyranoside. J. Struct. Chem. 2012, 53, 55-62. [CrossRef]

62. Nafee, S.S.; Hagar, M.; Ahmed, H.A.; El-Shishtawy, R.M.; Raffah, B.M. The synthesis of new thermal stable schiff base/ester liquid crystals: A computational, mesomorphic, and optical study. Molecules 2019, 24, 3032. [CrossRef]

63. Ahmed, H.A.; Hagar, M.; Alhaddad, O.A. Phase behavior and DFT calculations of laterally methyl supramolecular hydrogenbonding complexes. Crystals 2019, 9, 133. [CrossRef]

64. Alnoman, R.; Ahmed, H.A.; Hagar, M. Synthesis, optical, and geometrical approaches of new natural fatty acids' esters/Schiff base liquid crystals. Molecules 2019, 24, 4293. [CrossRef] [PubMed]

65. Ahmed, H.; Hagar, M.; Saad, G. Impact of the proportionation of dialkoxy chain length on the mesophase behaviour of Schiff base/ester liquid crystals; experimental and theoretical study. Liq. Cryst. 2019, 46, 1611-1620. [CrossRef]

66. Hagar, M.; Ahmed, H.; El-Sayed, T.; Alnoman, R. Mesophase behavior and DFT conformational analysis of new symmetrical diester chalcone liquid crystals. J. Mol. Liq. 2019, 285, 96-105. [CrossRef]

67. Ahmed, H.; Hagar, M.; Aljuhani, A. Mesophase behavior of new linear supramolecular hydrogen-bonding complexes. RSC Adv. 2018, 8, 34937-34946. [CrossRef]

68. Ahmed, H.; Hagar, M.; Alhaddad, O. New chair shaped supramolecular complexes-based aryl nicotinate derivative; mesomorphic properties and DFT molecular geometry. RSC Adv. 2019, 9, 16366-16374. [CrossRef]

69. Abdullah Alshabanah, L.; Al-Mutabagani, L.A.; Ahmed, H.A.; Hagar, M. Induced wide nematic phase by seven-ring supramolecular H-bonded systems: Experimental and computational evaluation. Molecules 2020, 25, 1694. [CrossRef]

70. Alhaddad, O.A.; Abu Al-Ola, K.A.; Hagar, M.; Ahmed, H.A. Chair-and V-Shaped of H-bonded supramolecular complexes of azophenyl nicotinate derivatives; mesomorphic and DFT molecular geometry aspects. Molecules 2020, 25, 1510. [CrossRef] [PubMed]

71. Zaki, A.A.; Hagar, M.; Alnoman, R.B.; Jaremko, M.; Emwas, A.-H.; Ahmed, H.A. Mesomorphic, Optical and DFT Aspects of Near to Room-Temperature Calamitic Liquid Crystal. Crystals 2020, 10, 1044. [CrossRef]

72. Al-Mutabagani, L.A.; Abdullah Alshabanah, L.; Ahmed, H.A.; Abu Al-Ola, K.A.; Hagar, M. New Rod-Like H-Bonded Assembly Systems: Mesomorphic and Geometrical Aspects. Crystals 2020, 10, 795. [CrossRef]

73. Al-Mutabagani, L.A.; Alshabanah, L.A.; Naoum, M.M.; Hagar, M.; Ahmed, H.A. Experimental and computational approaches of newly polymorphic supramolecular H-bonded liquid crystal complexes. Front. Chem. 2020, 8, 571120. [CrossRef]

74. Chen, R.; An, Z.; Wang, W.; Chen, X.; Chen, P. Lateral substituent effects on UV stability of high-birefringence liquid crystals with the diaryl-diacetylene core: DFT/TD-DFT study. Liq. Cryst. 2017, 44, 1515-1524. [CrossRef]

75. Kirsch, P.; Bremer, M. Understanding fluorine effects in liquid crystals. ChemPhysChem 2010, 11, 357-360. [CrossRef]

76. Subhapriya, P.; Sadasivam, K.; Mohan, M.M.; Vijayanand, P. Experimental and theoretical investigation of p-n alkoxy benzoic acid based liquid crystals-A DFT approach. Spectrochim. Acta Part A Mol. Biomol. Spectrosc. 2014, 123, 511-523. [CrossRef] [PubMed]

77. Sundaram, S.; Jayaprakasam, R.; Dhandapani, M.; Senthil, T.; Vijayakumar, V. Theoretical (DFT) and experimental studies on multiple hydrogen bonded liquid crystals comprising between aliphatic and aromatic acids. J. Mol. Liq. 2017, $243,14-21$. [CrossRef]

78. Paterson, D.A.; Abberley, J.P.; Harrison, W.T.; Storey, J.M.; Imrie, C.T. Cyanobiphenyl-based liquid crystal dimers and the twist-bend nematic phase. Liq. Cryst. 2017, 44, 127-146. [CrossRef] 